\title{
Tecnologias digitais, leitura e produção textual: contextualizando discussões a partir do uso do blog em uma experiência de ensino
}

\author{
Digital technologies, reading and textual production: contextualizing \\ discussions from the use of the blog in a teaching experience
}

Lilian Lemos Menegaro ${ }^{1}$

\begin{abstract}
Resumo
São apresentadas neste relato de experiência algumas considerações observadas em uma prática de ensino, realizada nas aulas de Língua Portuguesa de uma turma de $9^{\circ}$ ano, em uma escola da rede pública municipal. A prática teve a finalidade de usar o blog como tecnologia digital para desenvolver habilidades de leitura e produção textual, através dos gêneros reportagem e comentário. Sendo assim, as considerações estão centradas no desenvolvimento da competência comunicativa dos estudantes, priorizando as possibilidades de articulação de múltiplos elementos de linguagem no uso do blog para a interação, sem deixar de problematizar fatores como a desigualdade social, que exclui muitas pessoas desse uso. Essa experiência evidenciou aspectos primordiais, tais como o fato de que os estudantes estão habituados a utilizar algumas tecnologias e possuem dificuldade em manipular outras que são consideradas básicas. Houve um grande ganho na compreensão do processo de articulação de diferentes recursos de linguagem e sua produção de sentidos. Ressalta-se a tomada de consciência necessária ao pensamento crítico e a autonomia, inerentes às práticas sociais nos/dos espaços virtuais, que também são modos de agir no mundo.
\end{abstract}

Palavras-chave: Tecnologias digitais. Leitura e produção textual. Blog.

\begin{abstract}
In this experience report, I present some considerations observed during a teaching practice taken place in a 9th grade Portuguese Language class at a public school. Such a pedagogical practicum aimed to use the blog as a digital technology to assist in the development of students' reading and writing skills, focusing on the use of "news report" and "comments" as textual genres. Therefore, the striking points of this activity led to the development of students' communicative competence, prioritizing the possibilities of articulating multiple modes of text in the blog-sphere as means of interaction. In the process, we problematized factors such as social inequality and how it might exclude social agents from this context of language usage. This experience highlights some fundamental aspects as the fact that although students were used to using some technological tools, they sometimes found it challenging to deal with common types of software. There has been a considerable gain from understanding the process and articulating different language resources to produce meaning. However, special attention should be drowned to the need for awareness-raising for critical thinking and autonomy, qualities inherently crucial for them to effectively navigate in social practices on virtual spaces, also considered ways of acting in the social world.
\end{abstract}

Keywords: Digital technology. Reading and textual production. Blog.

\section{Introdução}

As observações apresentadas neste texto decorrem de uma experiência de ensino realizada na disciplina de Língua Portuguesa, em uma escola da rede pública municipal, com uma turma de $9^{\circ}$ ano do Ensino Fundamental, composta por 16 estudantes na faixa etária de 14 a 15 anos. 0 objetivo principal da prática consistiu em usar o blog como tecnologia digital para o desenvolvimento de habilidades de

\footnotetext{
1 Mestra em Letras. Universidade Federal do Rio Grande (FURG), Rio Grande, Rio Grande do Sul, Brasil. Orcid: https://orcid.org/0000-0002-2249-0245. E-mail: menegarolilian@gmail.com.
}

LínguaTec, Instituto Federal de Educação, Ciência e Tecnologia do Rio Grande do Sul, Bento Gonçalves 
leitura e produção textual, através dos gêneros reportagem e comentário. Esta narrativa visa apresentar alguns pontos observados nessa prática, abrangendo fatores essenciais, como o uso das tecnologias digitais para o desenvolvimento da competência comunicativa e formação da autonomia e do pensamento crítico dos estudantes nas aulas de Língua Portuguesa.

Os ambientes virtuais têm ganhado cada vez mais espaço e, junto de inúmeros programas $e$ aplicativos de edição de texto, estão possibilitando que os sujeitos manipulem diferentes elementos de linguagem para produzir sentidos. O blog apresenta-se como uma dessas tecnologias digitais que ampliam as possibilidades de manipulação da linguagem, tratando-se de um ambiente propício à finalidade educativa, uma vez que pode ser organizado exclusivamente para o desenvolvimento das atividades propostas. Já os gêneros textuais reportagem e comentário são amplamente usados nos espaços virtuais de interação.

As considerações aqui apresentadas fundamentam-se em estudos e pesquisas que tratam da educação, do uso das tecnologias digitais, da relação entre a linguagem e essas tecnologias nas aulas de língua materna, além de considerar também os gêneros textuais. As seções 2, 3 e 4, que compõem esse texto, estão divididas da seguinte forma: a) primeiramente, a prática de ensino é situada a partir de considerações sobre os aspectos que envolvem o uso do blog como recurso pertinente para a aprendizagem nas aulas de Língua Portuguesa; b) em seguida, focaliza-se as análises a partir dos sujeitos envolvidos na referida prática; e c) por fim, é dado destaque para os gêneros textuais trabalhados, evidenciando-se que a relação entre as tecnologias digitais, a linguagem e o processo educacional é o cerne de todas as análises desenvolvidas.

\section{Situar a prática de ensino, pensar os novos modos de interação e considerar a relevância dos blogs e do uso de tecnologias digitais nas aulas de Língua Portuguesa}

Este relato apresenta considerações desenvolvidas a partir de uma experiência de ensino na disciplina de Língua Portuguesa, realizada em uma escola da rede pública municipal, situada na periferia. Dessa forma, diante da realidade de grande parte das escolas públicas brasileiras, é fundamental pontuar que na escola em questão, havia uma sala de informática com os recursos básicos necessários para 0 desenvolvimento das atividades propostas, entre os quais estão inclusos computadores em bom estado e acesso à Internet de boa qualidade. 
As atividades foram organizadas basicamente da seguinte forma: foi criado o blog 2 da turma no qual foi postada uma reportagem ${ }^{3}$ por semana, durante quatro semanas, para que os estudantes lessem e escrevessem comentários, após diálogo na turma sobre o assunto abordado. Nesse processo, a cada aula em que eram lidas as reportagens, além da discussão quanto ao assunto tratado, eram trabalhados aspectos formais, considerando as características dos gêneros textuais reportagem e comentário, junto a questões de linguagem e análise linguística ${ }^{4}$. Além disso, foram discutidas questões referentes ao comportamento das pessoas na Internet, tendo em vista o grande número de comentários e posts que violam princípios básicos de respeito o que, infelizmente, tornou-se uma prática comum nos espaços virtuais.

Após essas semanas de leituras, discussões e escritas, a turma foi dividida em quatro grupos e cada um deles produziu uma reportagem para ser postada no blog. Em votação na turma, o tema escolhido pelos estudantes para a produção das reportagens foi "música no recreio", motivados por um debate que já acontecia na turma sobre as músicas que eram tocadas no sistema de áudio da escola, durante 0 intervalo. Alguns alunos reclamavam das músicas, enquanto outros defendiam e outros ainda protestavam que não eram reproduzidas as músicas solicitadas. A princípio, o tema da reportagem seria livre, mas dada à proporção que o assunto tomou na turma, e na escola de modo geral, todos os grupos optaram por abordar o tema citado.

Para a atividade, os alunos entrevistaram professores, outros alunos da escola e um dos grupos entrevistou o monitor responsável pelo sistema de áudio. As reportagens produzidas pelos grupos foram lidas por todos os colegas, ao passo que cada estudante escreveu um comentário para cada uma delas. O blog foi divulgado na escola de forma que alguns professores acessaram e conversaram com os estudantes sobre as postagens.

Quando são mencionados os espaços virtuais de interação, logo se pensa nas redes sociais, e é possível que o leitor se pergunte por que a escolha pelo blog e não pelo uso de alguma dessas redes. Como grande parte dos adolescentes, os estudantes com os quais as atividades foram realizadas, possuem perfil em redes como Facebook e Instagram. Entretanto, a opção pelo blog ocorreu tendo em

\footnotetext{
20 blog foi criado em aula. Como os alunos não sabiam como fazer, eles acompanharam todo o processo que foi projetado via aparelho de multimídia, disponivel no laboratório de informática. Eles fizeram algumas perguntas e muitos comentários. ${ }^{3}$ As reportagens foram originalmente publicadas em sites de jornais ou revistas e a publicação no blog da turma foi feita com a devida contextualização e referência à publicação original. É necessário destacar que todas as reportagens selecionadas tratavam de algum tema relacionado à vida escolar.

${ }^{4}$ Nessa dinâmica foi realizada a leitura de cada um dos comentários e na aula seguinte trabalhadas questões que mais se destacaram e/ou repetiram, a fim de que nos próximos comentários os estudantes desenvolvessem a escrita revendo os aspectos trabalhados. 0 uso da vírgula, elementos de sintaxe, como a ordem do sujeito, verbo e predicado, e a escolha do vocabulário foram os aspectos linguísticos mais trabalhados, de acordo com as dificuldades que os próprios estudantes apresentaram.
} 
vista a finalidade pedagógica do uso, pois mesmo sendo um espaço virtual público, o nível de alcance é infinitamente menor, considerando a criação de um blog da turma especificamente para as atividades pedagógicas, sem divulgação ampla.

Dessa forma, os estudantes não se sentiram tão expostos e nem intimidados, o que favoreceu 0 desenvolvimento da escrita. As redes sociais se caracterizam principalmente pela superexposição e pelo grande alcance que as publicações podem atingir, o que pode inibir o desenvolvimento da produção textual, quando essa deve ser realizada no contexto de atividade escolar. Eram reconhecidas as dificuldades de escrita dos estudantes, porém era igualmente reconhecida a necessidade de que eles pensassem a leitura e a escrita no/para o ambiente virtual, já que esse é um espaço no qual eles interagem cada vez mais.

Ao colocar todos esses fatores em pauta, torna-se importante uma breve nota introdutória para fazer referência exclusivamente ao blog. Com a consolidação de outras tecnologias digitais, especialmente as redes sociais, há certo imaginário no senso comum de que o blog é um ambiente virtual ultrapassado. Porém, diferente de ambientes que se tornaram obsoletos, como o caso do hoje extinto Orkut, os blogs permanecem sendo muito utilizados. Ocorre que, ao longo dos seus mais de 20 anos de existência, suas potencialidades se ampliaram e houve uma ressignificação do seu uso.

A dinâmica das tecnologias digitais de informação e comunicação (TDIC's) tende a se caracterizar principalmente pela mudança rápida de recursos disponíveis, o que altera em diferentes níveis os modos de interação. Surgidos inicialmente como "diários virtuais", os blogs foram um dos primeiros recursos digitais que se configuraram como espaços de expressão e exposição, permitindo que seus usuários expusessem suas opiniões, rotinas, gostos pessoais, trabalhos e modos de vida. Ao analisar o uso do blog na educação, Gutierrez (2005) afirma que esses espaços se caracterizam, dentre outros aspectos, "[...] por serem contextualizados e enriquecidos por comentários; por serem frequentemente atualizados; por terem as postagens mais antigas arquivadas, permanecendo à disposição, por serem intertextuais e interdependentes, possuindo ligação com outros textos" (GUTIERREZ, 2005, p. 3-4).

Com o passar do tempo, esses ambientes foram ganhando mais ferramentas de edição de textos, de interação entre os usuários e as possibilidades de ampliação para a produção de conteúdo gerou uma mudança na forma como essas plataformas eram usadas. No contexto atual, os blogs são utilizados para uma infinidade de propósitos que vão desde a publicação de textos jornalísticos como notícias, entrevistas e reportagens, roteiros e experiências de viagens, rotinas de beleza, moda, culinária, materiais pedagógicos até compra e venda de produtos e serviços. 
Atualmente, além do compartilhamento de informações e experiências pessoais, há também nichos de assuntos que classificam esses espaços. Há, por exemplo, os blogs de viagem, de notícia, de moda, de culinária, dentre outros. A partir da expansão de recursos e da categorização por assuntos, 0 que tornou esses ambientes mais atrativos, ele passou a ser também uma fonte de renda e um meio de trabalho ${ }^{5}$. Assim, surgiu o termo "blogueira/blogueiro" ${ }^{6}$, que é usado como referência para denominar pessoas que usam o blog para produzir conteúdo e fazem disso sua profissão.

Fato é que de modo diferente, desde o seu surgimento, o que decorre inclusive do próprio desenvolvimento de recursos tecnológicos e da forma como os indivíduos se adequam a ele, o blog ainda é muito utilizado e cumpre seu papel nas práticas sociais de interação. Como um ambiente de interação, portanto de uso da linguagem, ele apresenta-se como adequado para experiências pedagógicas, especialmente no âmbito da educação linguística.

O blog é uma tecnologia digital com diversas possibilidades de manejo da linguagem, seja pelos próprios recursos que os servidores disponibilizam, seja porque permite a publicação e compartilhamento de textos produzidos em outras ferramentas. Nele, é possível postar uma multiplicidade de gêneros textuais, usando escrita, imagens, vídeos, sons, cores, ou seja, produções que envolvem a articulação dos mais variados modos de linguagem. Portanto, ele pode funcionar concomitantemente como um recurso para produzir e editar textos e como uma plataforma para publicar textos produzidos em outras ferramentas digitais. Na prática de ensino aqui mencionada ele foi usado das duas formas.

Nesse sentido, um dos fatores fundamentais para o ensino de língua materna na escola é a forma como o professor concebe a linguagem, pois é essa concepção que irá orientar sua prática de ensino. No que se refere ao trabalho com tecnologias digitais nas aulas de língua materna, é primordial a concepção da própria linguagem como um espaço de interação. Nesse âmbito, entende-se que é na, e pela linguagem, que os sujeitos interagem situados em um contexto social, histórico, cultural.

O ensino de Língua Portuguesa, nessa perspectiva, está alicerçado em uma concepção sociointeracionista, na qual a linguagem, conforme Koch (2003, p. 19), é vista como "lugar de 'inter-ação' entre sujeitos sociais, isto é, sujeitos ativos, empenhados em uma atividade sociocomunicativa". É praticamente impossível pensar práticas sociais de comunicação na atualidade, sem pensar nas tecnologias digitais. O blog é um recurso tecnológico em que as atividades sociocomunicativas são

\footnotetext{
5 É importante mencionar que há uma série de problematizações que devem ser feitas com relação ao trabalho informal e produção de conteúdo para a internet. Contudo, essa problematização ultrapassa os limites e objetivos desse trabalho.

6 O termo "digital influencer" também pode ser usado para quem usa blog, mas atualmente se aplica de modo mais apropriado para quem usa as redes sociais como meio profissional.
} 
altamente multimodais e exigem dos estudantes competências específicas de leitura e produção textual.

Em conformidade com o pensamento de Bakhtin (1997), é necessário compreender o uso das TDIC's como mais uma esfera da atividade humana, cujo impacto na sociedade contemporânea é muito significativo. A respeito do uso da língua, Bakhtin (1997, p. 279) considera que

\begin{abstract}
efetua-se em forma de enunciados (orais e escritos), concretos e únicos, que emanam dos integrantes duma ou doutra esfera da atividade humana. 0 enunciado reflete as condições específicas e as finalidades de cada uma dessas esferas, não só por seu conteúdo (temático) e por seu estilo verbal [...] mas também, e sobretudo, por sua construção composicional. Estes três elementos (conteúdo temático, estilo e construção composicional) fundem-se indissoluvelmente no todo do enunciado, e todos eles são marcados pela especificidade de uma esfera de comunicação.
\end{abstract}

É necessário considerar que na construção composicional situam-se elementos de linguagem que não só o verbal. Houve significativas transformações nas práticas sociais de interação provocadas pelas tecnologias digitais de comunicação. Considerando a infinidade de recursos que essas tecnologias permitem utilizar, as aulas devem acontecer como momentos em que os estudantes sejam incentivados a mobilizar os usos da linguagem em situações concretas de interação.

Há anos pesquisando questões de tecnologia e linguagem, Ribeiro (2015) observa que vivemos em um cenário complexo no qual convivem processos de leitura e escrita que se materializam de diversas formas. Para a pesquisadora, "não aprendemos, cegamente, modos de produzir sentidos vindos de uma instância superior, inalcançável. Ao contrário, a escrita e a leitura estão misturadas a nossos modos de vida, às nossas vivências, ao nosso modo de operar em sociedade" (RIBEIRO, 2015, p. 4). Dentre essas novas vivências, destaca-se a interação mediada pelas tecnologias digitais.

Levy (1997) já afirma desde os anos 1990 que o ciberespaço possibilita o exercício da democracia. Assim, os estudantes necessitam desenvolver a capacidade crítica a fim de que não estejam nos espaços virtuais reproduzindo mecanicamente conteúdos e informações. É fundamental que o desenvolvimento da autonomia, do pensamento crítico, contemple não só os processos de leitura de signos verbais, mas a capacidade de mobilizar habilidades para a produção de textos que também utilize múltiplos elementos de linguagem, os não verbais.

\title{
3 Pensar a educação e as tecnologias digitais a partir dos sujeitos
}

Além dos elementos de contextualização relacionados à escola, devem ser pontuadas também informações sobre os estudantes. Isso porque além de serem os atores centrais de toda a prática 
pedagógica, alguns aspectos que emergiram no decorrer das atividades desenvolvidas ajudam a pensar a complexidade do uso das tecnologias digitais na educação, de modo a não fazer análises e suposições descoladas da realidade social e, consequentemente, das experiências dos estudantes enquanto sujeitos que vivem em um determinado tempo e espaço.

Considerando o foco desse trabalho, destaco como informação essencial o fato de que todos esses estudantes vinham de famílias em situação de vulnerabilidade social, algumas mais acentuadas, outras menos. Nenhum deles possuía computador em casa, mas todos possuíam acesso a smartphones, por dispositivos próprios ou o dos pais. Todos eles relataram dificuldade em usar a Internet devido aos custos dos pacotes de dados das operadoras, ao passo que nenhum demonstrou possuir rede de Wi-Fi ou alguma tecnologia similar para acessar a rede em casa.

Apesar dessas informações serem a respeito de uma turma específica, as pesquisas mostram que elas representam grande parte dos estudantes da rede pública de ensino no Brasil 7 . Em pesquisa divulgada pelo Comitê Gestor da Internet no Brasil (2018) é possível observar que o acesso à Internet por banda larga cresceu em domicílios brasileiros. No entanto, é preciso fazer o devido recorte:

as desigualdades por classe socioeconômica e por áreas urbanas e rurais persistem: 0 acesso à Internet está presente em $30 \%$ dos domicílios de classe D/E (proporção era de $23 \%$ em 2016 ) e $34 \%$ das residências da área rural (em 2016, era 26\%). Já nas classes A e B, as proporções atingem, respectivamente, 99\% e 93\%. Além disso, 19\% dos domicílios conectados não possuem computador, o que representa 13,4 milhões de residências. Essa proporção era de apenas 4\% em 2014.

Segundo o estudo, o preço da conexão permanece como principal motivo mencionado para a ausência de Internet nos domicílios: $27 \%$ dos entrevistados afirmam que o serviço é caro [...]. No que diz respeito ao principal tipo de conexão, a TIC Domicílios 2017 registrou estabilidade em relação ao ano anterior, seja por residência conectada por banda larga fixa (64\%) ou móvel $3 G$ ou $4 G(25 \%)$. O acesso móvel, no entanto, continua sendo mais utilizado do que o fixo por domicílios de classes D/E (48\%) (COMITÊ GESTOR DA INTERNET NO BRASIL, 2018, não paginado).

A possibilidade de acesso via dados móveis fica ainda mais comprometida em um cenário de acentuado aumento das desigualdades sociais que estamos vivendo no Brasil nos últimos anos. $\mathrm{A}$ pesquisa mencionada também mostra que "a metade dos indivíduos conectados acessa a Internet exclusivamente pelo celular" (COMITÊ GESTOR DA INTERNET NO BRASIL, 2018, não paginado). Diante disso, destaca-se que utilizar a sala de informática da escola foi também uma forma de familiarizar os estudantes com o uso do computador, uma vez que eles não têm contato com esse dispositivo em seu cotidiano. Fatores como esse são propícios para refletir a respeito da ideia de que os jovens dominam 0 uso dessas tecnologias, enquanto pessoas mais velhas possuem dificuldades. Prensky (2001)

\footnotetext{
7 Essas informações corroboram a necessidade de manter uma posição crítica contrária às investidas de implementar a modalidade EaD na educação básica.
} 
denominou esses dois grupos como nativos e imigrantes digitais. Ao desenvolver uma análise crítica dessa ideia, Ribeiro (2019) considera aspectos aos quais devemos estar atentos:

\begin{abstract}
a chegada das tecnologias digitais, em especial do computador e da internet, ocorreu em um ponto discreto de nossa linha do tempo, em nossa história (humana e individual), o que quer dizer que todas as pessoas foram afetadas por isso, embora certamente de maneira desigual não apenas por serem, em tese, menos ou mais capazes de aprender sobre novas tecnologias, [...] mas também, e talvez principalmente, porque temos acessos, necessidades, papéis e desejos muito diferentes entre nós (RIBEIRO, 2019, p. 11).
\end{abstract}

Nesse ponto, cabe uma observação quanto à ideia, que paira no senso comum, de que por serem nascidos na "era digital" os adolescentes dominam o uso de toda e qualquer tecnologia digital. A experiência pedagógica realizada trouxe exemplos que mostram como essa ideia é equivocada. Primeiro, foi necessário que os alunos criassem e-mails para poder fazer comentário no blog e nenhum deles sabia como acessar e usar e-mails, embora todos possuíssem perfis em redes sociais. Além disso, nenhum deles sabia como editar textos em blogs e tampouco usar uma ferramenta considerada básica como 0 Word. Além disso, alguns não sabiam usar o teclado do computador para acentuar palavras e usar símbolos como sinal de mais ou igual. Essa constatação pode estar relacionada ao fato de que eles não estão habituados a usar o computador.

Obviamente, esse é um dado relevante e precisa ser considerado, principalmente quando se está ciente do papel social da escola. Com a proposta de construir o que denominaram ser uma matriz de letramento digital, Dias e Novais (2009) afirmam que ele não é um curso de informática, porém "envolve também a lide com um portador de textos: o computador" (DIAS; NOVAIS, 2009, p. 5). Na próxima seção, serão apresentados alguns pontos a respeito do letramento digital.

Por ora, fica a seguinte reflexão: se é verdade que não cabe ao professor de Língua Portuguesa ser professor de informática, considerando ainda que por algumas vezes o próprio professor não sabe usar esses programas, sites e aplicativos, é igualmente verdade que como professores não é coerente negar a responsabilidade diante desse desafio, que se impõe cada vez mais e hoje já é próprio da tarefa profissionale.

Ademais, relatos de professores em diversas circunstâncias de experiência de ensino têm apontado que é comum os estudantes não dominarem o uso de ferramentas consideradas básicas, como o Word e o e-mail. Os mesmos estudantes que interagem em redes sociais, fazem vídeos, editam imagens, participam de jogos virtuais com algum nível de complexidade para a maioria das pessoas, apresentam dificuldades para manusear e explorar ferramentas consideradas básicas. Ocorre que muitos

8É essencial cobrar políticas públicas para a educação básica que contemplem programas de formação continuada qualificados a fim de auxiliar os professores nessa tarefa complexa, difícil, mas necessária. 
desses são recursos digitais ainda utilizados com frequência no cotidiano nas mais variadas atividades. Esses são recursos que estão em uso, fazem parte da realidade social em ampla escala e exigem o uso da linguagem.

\section{Considerações específicas sobre desenvolvimento de leitura e produção textual a partir dos gêneros textuais reportagem e comentário}

Discutidos até o momento aspectos mais gerais que envolveram o blog, a linguagem e as tecnologias digitais na prática de ensino, cabe destacar agora elementos mais específicos no âmbito do trabalho com os gêneros textuais reportagem e comentário. A escolha pelo comentário deu-se porque esse é um dos gêneros mais utilizados atualmente na Internet, principalmente nas redes sociais. As interações verbais nesses espaços acontecem muito através dos comentários, que são textos curtos, objetivos, que exigem habilidades de expressão verbal em poucas palavras, o que pode ser bastante desafiador no uso da língua, principalmente quando se trata de comentar sobre assuntos complexos.

Por outro lado, a reportagem é um texto mais longo, que requer pesquisa sobre o tema, pode envolver entrevistas, visitas a lugares, requer escolha e edição de imagens, dentre outros fatores que exigem mais empenho no manejo de diferentes modos de linguagem. Tendo em vista a proposta de divisão da turma em grupos, a reportagem foi escolhida também, por ser um gênero que favorece a dinâmica de trabalho em equipe.

As tecnologias digitais estão influenciando também, em alguma medida, a reconfiguração de gêneros textuais, assim como novas relações entre eles. No caso da reportagem e do comentário notase que antigamente a relação entre esses gêneros não era tão direta. Antes da Internet, para comentar alguma reportagem o leitor podia enviar carta à revista ou ao jornal, que poderia publicá-la ou não. Hoje, no momento em que a reportagem é publicada na Internet, já é possível que o leitor faça o seu comentário diretamente na página ${ }^{9}$. Trata-se de uma nova forma de configuração dos gêneros e, consequentemente, da interação entre os sujeitos. Há uma significativa maleabilidade tanto na produção quanto na relação entre os gêneros. Marcuschi (2003, p. 19) caracteriza os gêneros "como eventos textuais altamente maleáveis, dinâmicos e plásticos" que "surgem emparelhados a necessidades e atividades sócioculturais (...)". A reportagem e o comentário não são gêneros novos, mas a relação entre eles foi ressignificada com a Internet.

\footnotetext{
${ }^{9}$ Em algumas páginas há a possibilidade de desativar os comentários, logo, se essa opção for ativada por quem fez a publicação, o leitor fica impedido de expor sua opinião.
} 
A partir da concepção sociointeracionista de linguagem, reconhecendo a importância do texto, é priorizada a proposta que sugere a articulação entre as práticas de leitura, produção de textos e análise linguística, conforme o pensamento de Geraldi (2006). Ocorre que com o uso frequente das TDIC's no cotidiano $^{10}$, essas três práticas que alicerçam o ensino de língua materna na escola devem, na medida do possível, ser consideradas na perspectiva dos espaços virtuais tanto quanto dos espaços não-virtuais.

Durante o processo de produção da reportagem, foi possível observar que os estudantes, embora tivessem muitas limitações no uso da ferramenta, estavam bastante preocupados em produzir 0 texto, introduzindo elementos como imagens, cores, tamanhos e modelos de fontes. Como as características desse gênero textual foram trabalhadas no momento de análise das reportagens lidas, eles mostraram ter conhecimento da importância desses elementos para o texto quando foram produzir uma reportagem.

O processo do trabalho em equipe dos grupos foi bastante satisfatório. As atividades como entrevistas, captação de imagens, pesquisa de dados, escrita do texto, foram divididas entre os membros do grupo, sendo que havia todo um planejamento de como o assunto seria abordado para que houvesse coerência. No momento de articular esses elementos, o grupo se reuniu e o fez em conjunto, lendo, dialogando e, principalmente, explorando a ferramenta digital de edição do texto. Alguns demonstraram interesse em gravar vídeos para compor a reportagem, uma vez que seria postada no blog da turma, mas devido a desentendimentos nos dois grupos que levantaram essa possibilidade, a ideia não se concretizou. De qualquer forma, mostra que eles estavam pensando sobre os recursos de linguagem possíveis e sua relação com o gênero textual e o espaço no qual seria publicado.

Nesse contexto, um aspecto que se mostrou relevante foi a necessidade de que a leitura contemplasse elementos não verbais, pois na primeira reportagem lida, os estudantes ignoraram completamente as imagens. Havia três fotos no texto, porém, no momento da discussão, ninguém as mencionou, sendo que duas delas eram citadas verbalmente. Quando foram questionados se não iam falar sobre as imagens, uma aluna respondeu "professora, a senhora mandou a gente ler". Observem qual é a ideia de leitura que essa estudante possui, imaginem em um universo altamente imagético, como é o digital, o quanto a leitura desses estudantes estava sendo limitada.

A concepção de texto ainda está fortemente relacionada ao signo verbal, o que nunca esteve em consonância com a concepção de texto como uma atividade social. Essa se torna uma concepção

\footnotetext{
10 É preciso ponderar que na atual conjuntura social brasileira, não se pode dizer que há a universalização do acesso e consequentemente que há igualdade no acesso à Internet. Ao contrário, como já foi mostrado nesse trabalho, a desigualdade ainda é muito grande e ainda são várias as barreiras a serem enfrentadas em nosso país para que as pessoas possam de fato usar as tecnologias digitais, principalmente a econômica.
} 
ainda mais inapropriada com os níveis de multimodalidade que há nos textos produzidos e publicados em ambientes digitais. A produção textual deve ocorrer como um processo no qual o estudante tornase um leitor-produtor crítico, que pensa sobre os usos que são feitos e os usos que ele faz da linguagem, enquanto está agindo socialmente. Nesse caso, o agir socialmente implica o uso das tecnologias digitais. Eles já mobilizam inúmeros elementos de linguagem de forma quase intuitiva quando usam a Internet, o que não é ruim, mas precisa ser trabalhado para que compreendam inclusive a sua posição enquanto sujeitos sociais.

Durante o processo de leitura do material que era publicado no blog, escrita dos comentários e elaboração das reportagens, foi necessário ensiná-los a usar recursos que para muitas pessoas são corriqueiros. O Word, por exemplo, foi utilizado junto ao blog, a pedido dos estudantes, para sistematizar a escrita da reportagem e, por vezes, dos comentários, antes de publicá-los. É possível que isso tenha ocorrido porque houve certa preocupação com o monitoramento da escrita, tendo em vista a publicação do conteúdo e, portanto, sua disponibilidade para que qualquer pessoa tivesse acesso. Dos quatro grupos formados, apenas um escreveu a reportagem diretamente no blog. Os demais preferiram usar 0 Word para editar e posteriormente colaram no espaço destinado à edição no blog, fazendo os ajustes necessários.

Observar a forma como os estudantes lidaram com o uso dessas tecnologias corrobora a necessidade de pensar aspectos básicos de letramento digital, que no conceito de Ribeiro e Coscarelli (2020, não paginado) "diz respeito às práticas sociais de leitura e produção de textos em ambientes digitais, isto é, ao uso de textos em ambientes propiciados pelo computador ou por dispositivos móveis [...]". As pesquisadoras acrescentam que "ser letrado digital implica saber se comunicar em diferentes situações, com propósitos variados, nesses ambientes, para fins pessoais ou profissionais" (RIBEIRO; COSCARELLI, 2020, não paginado).

Quanto às competências exigidas para que se desenvolva o letramento digital, Dias e Morais (2009, p. 5) apontam o que chamaram de "ações de usuários competentes". Para os autores, as competências são: "utilizar diferentes interfaces; buscar e organizar informações em ambiente digital; ler hipertexto digital e produzir textos (orais ou escritos) para ambientes digitais" (DIAS; MORAIS, 2009, p. $5)$.

Assim, as interlocuções que ocorreram no processo de ler-escrever em espaços digitais passaram pelo aluno enquanto leitor do texto do outro e pelo aluno enquanto leitor do próprio texto, que o escreveu ciente de que havia leitores para a sua produção. Nesse sentido, Koch (2003) considera que o produtor e o interpretador do texto são "estrategistas", na medida em que, ao jogarem o "jogo da linguagem", mobilizam uma série de estratégias - de ordem sociocognitiva, interacional e textual - com 
vistas à produção do sentido" (KOCH, 2003, p. 18). É possível afirmar, então, que o uso das tecnologias digitais, favorece e incentiva uma manipulação estratégica da linguagem, influenciando a formação desse sujeito que age socialmente.

Embora todo texto, antes mesmo da disponibilidade dos recursos digitais, tenha algum grau de multimodalidade, ou seja, a multimodalidade é um traço inerente a qualquer texto, é evidente que a amplitude de possibilidades dada por esses recursos aumentou e intensificou a multimodalidade nas produções textuais. Hoje, é possível mobilizar mais recursos semióticos, ou seja, um único texto pode ser produzido articulando sons, movimentos, imagens e cores, por exemplo. Esses aspectos foram compreendidos pelos estudantes enquanto estavam no processo de construção das reportagens, além disso, passaram a considerar todos esses recursos durante o processo de leitura. A relação textomultimodalidade-tecnologias digitais pode ser compreendida como

\footnotetext{
um 'tecer' junto, um objeto fabricado que é formado por fios 'tecidos juntos' - fios constituídos de modos semióticos. Esses modos podem ser entendidos como formas sistemáticas e convencionais de comunicação. Um texto pode ser formado por vários modos semióticos (palavras e imagens, por exemplo) e, portanto, podemos chegar à noção de multimodalidade. Com 0 advento de materiais computadorizados, multimídia e interacional, esta forma de conceituar a semiose se torna cada vez mais pertinente (KRESS,1995, p.7).
}

Observa-se que é necessário ter cuidado para não usar as tecnologias digitais para reproduzir formas tradicionais de ensino como, por exemplo, o uso do Power Point meramente para substituir o quadro e o giz na exposição de conteúdo. Trata-se de usá-las sem perder de vista as possibilidades de uso efetivo nas práticas sociais, isto é, em situações de interação. Haja vista a importância dessa coerência na prática de ensino, pontua-se ainda que virtual e não-virtual não são meios opostos.

$\mathrm{Na}$ atual dinâmica social, eles se complementam, pois os sujeitos interagem tanto em um quanto no outro e, por vezes, concomitantemente. São espaços de leitura e de produção textual, que coexistem e se retroalimentam, entretanto, há certas especificidades que são próprias do universo digital que exigem determinados saberes. A educação humanizadora e libertadora, a formação do senso crítico, passa necessariamente pelo uso das tecnologias digitais, dada a realidade social de hoje.

\section{Considerações finais}

As escolas brasileiras estão muito longe de um cenário, no mínimo, satisfatório no que diz respeito à disponibilidade de tecnologias digitais. A desigualdade social em nosso país dificulta, e até impede, 0 acesso de milhares de estudantes a essas tecnologias. É preciso cobrar políticas públicas que ampliem o acesso da população à Internet e a dispositivos como smartphones, tablets e computadores, 
assim como políticas para a educação que contemplem investimento em tecnologias digitais para as escolas e na formação inicial e continuada dos professores. 0 uso dessas tecnologias deve ser feito dentro de um projeto de educação, que tenha compromisso social com as classes não privilegiadas.

A escola em que foi realizada a experiência relatada possui uma boa estrutura, que permitiu 0 desenvolvimento das atividades, o que foge à regra. A experiência exitosa, contudo, não pode permitir que a preocupação com o todo seja esquecida, por isso a menção a um contexto macro, que exige toda a atenção e requer muito da prática profissional na educação. Essa prática de ensino permitiu compreender a urgência de contemplar nas aulas possibilidades de explorar essas tecnologias, que se dá inevitavelmente pelo uso da linguagem. Ambientes digitais já se consolidaram como importantes espaços de interação, ampliando os modos de ação através da leitura e da escrita, do verbal e do não verbal. O uso do blog é uma realidade e como prática social requer o manejo adequado da linguagem. Já os gêneros reportagem e comentário permitem uma espécie de ordenação das ações comunicativas empreendidas nos ambientes virtuais, por isso a importância de trabalhar a linguagem sempre com um propósito comunicativo que se engendra a partir de gêneros.

Os estudantes demonstraram certo receio ao escrever os comentários e a reportagem diretamente no blog, aparentemente por ser uma atividade escolar. Mas, isso ocorreu pela preocupação com as escolhas que estavam fazendo, com o conteúdo que ia ser publicado, mesmo sabendo que não estavam sendo avaliados. 0 desenvolvimento do trabalho deu-se de forma colaborativa e a sugestão das atividades de leitura e produção textual foram bastante dialogadas, ou seja, essa preocupação veio pela consciência quanto ao impacto da articulação de suas escolhas e dos sentidos que ela produz.

Esse foi um fator positivo, porque a preocupação surgiu principalmente da tomada de consciência quanto à dimensão e importância que os processos de interação nos espaços virtuais ocupam em nossas vidas atualmente. Nesse sentido, um dos fatores mais positivos da experiência foi perceber o ganho dos adolescentes ao compreenderem o processo de manipulação de diferentes recursos de linguagem. Eles já usam esses recursos constantemente, mas o processo de pensar sobre, analisar, discutir criticamente com seus pares, potencializou esses usos. Outro ponto importante é que não é possível generalizar afirmando que todos os jovens sabem manusear todas as tecnologias digitais. Eles sabem de fato muitas coisas, possuem muitos conhecimentos nessa área, mas desconhecem também uma série de ferramentas, como foi possível constatar quando encontraram dificuldade ao usar o Word e o e-mail, por exemplo.

Essa tomada de consciência é importante para o desenvolvimento do pensamento crítico e da autonomia. Houve no decorrer das leituras e principalmente da escrita dos comentários, muitas discussões sobre a forma como as pessoas se expressam na Internet, uma vez que os próprios 
estudantes apontaram que "há muitas pessoas que passam dos limites", ou seja, há muito desrespeito e muita exposição descabida, aspectos sobre os quais precisamos dialogar. Os estudantes usam as ferramentas digitais fazendo escolhas e explorando possibilidades de manipulação da linguagem, porém precisam estar conscientes dessas escolhas, da forma como as fazem e do impacto que elas podem ter pelos sentidos que produzem, uma vez que ler e produzir textos nos ambientes virtuais também é um modo de agir no mundo.

\section{Referências}

BAKHTIN, Mikhail. Estética da Criação Verbal. Tradução de Maria Ermantina Galvão G. Pereira. 2. ed. Martins Fontes: São Paulo, 1997.

COMITÊ GESTOR DA INTERNET NO BRASIL. Acesso à Internet por banda larga volta a crescer nos domicílios brasileiros. 24 jul. 2018. Disponível em: https://cgi.br/noticia/releases/acesso-a-Internet-porbanda-larga-volta-a-crescer-nos-domicilios-brasileiros/. Acesso em: 23 jul. 2020.

DIAS, M. C.; NOVAIS, A. E. Por uma matriz de letramento digital. In: III Encontro Nacional sobre hipertexto. 2009. Belo Horizonte. Anais do III Encontro Nacional sobre hipertexto. Belo Horizonte: CEFET-MG, out. p. 1-19, 2009. Disponível em: http://nehte.com.br/hipertexto2009/anais/p-w/por-umamatriz.pdf. Acesso em: 27 mar. 2020.

GERALDI, João Wanderley (Org.). O texto na sala de aula. 4. ed. São Paulo: Ática, 2006.

GUTIERREZ, Suzana. Weblogs e educação: contribuição para a construção de uma teoria. RENOTE Revista Novas Tecnologias na Educação, Porto Alegre, V. 3, n. 1, Maio. 2005. Disponível em:<http://seer.ufrgs.br/renote/article/view/13731>. Acesso em: 25 nov. 2017.

KOCH, Ingedore Grunfeld Villaça. Desvendando os segredos do texto. 2. ed. São Paulo: Cortez, 2003.

KRESS, G. Writing the future: English and the Making of a Culture of Innovation. New York: Routledge, 1995.

LEVY, Pierre. Cibercultura. Editora 34: São Paulo, 1997

MARCUSCHI, Luiz Antônio. Gêneros textuais: definição e funcionalidade. In: DIONISIO, Angela; MACHADO, Anna Rachel; BEZERRA, Maria Auxiliadora. Gêneros textuais e ensino. Rio de Janeiro: Lucerna, 2003.

PRENSKY, Marc. Digital natives, digital immigrants. On the Horizon, MCB University Press, v. 9, n. 5, October, 2001. Disponível em: https://www.marcprensky.com/writing/Prensky\%20\%20Digital\%20Natives,\%20Digital\%20lmmigrants\%20-\%20Part1.pdf>. Acesso em: 15 dez. 2019.

RIBEIRO, Ana Elisa; COSCARELLI, Carla Viana. Letramento Digital. Glossário Ceale. Disponível em: http://www.ceale.fae.ufmg.br/app/webroot/glossarioceale/verbetes/letramento-digital. Acesso em: 13 mar. 2020. 
RIBEIRO, Ana Elisa. Do fosso às pontes: um ensaio sobre natividade digital, nativos jr. e descoleções. Revista da ABRALIN, v. 18, n. 1, p. 1-24, 14 nov. 2019. Disponível em: https://revista.abralin.org/index.php/abralin/article/view/1330/1309. Acesso em: 17 mar. 2020.

RIBEIRO, Ana Elisa. Tecnologia e poder semiótico: escrever, hoje. Periódico Texto Livre: Linguagem e

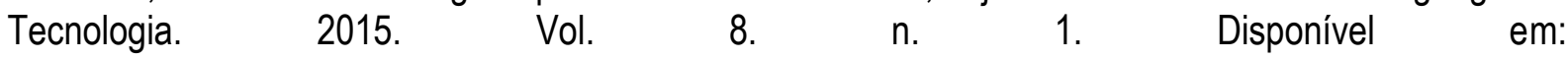
http://www.periodicos.letras.ufmg.br/index.php/textolivre/article/view/8681/7701. Acesso em: 10 out. 2019.

Data de submissão: 21/09/2020. Data de aprovação: 26/10/2020. 